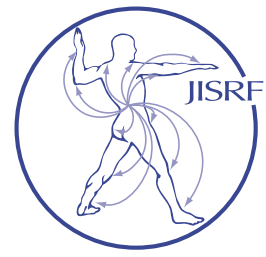

\title{
Search Engine Optimization for Medical Publishing
}

Faroo $D^{1}$

\begin{abstract}
Search engine optimization is becoming increasingly important for medical publishing professionals. They know the value of writing papers and articles that help expand the knowledge of their specific area of expertise. They also know that in today's online environment their publications need to be found in relevant web searches to be cited by fellow researchers. But if authors ignore the basics of keyword research and search engine optimization they run the risk of their research being lost in a vast sea of search results. What good is all that work if it never reaches the intended audience? The purpose of this commentary is to provide submitting authors basic yet important suggestions to help optimize their articles for online publishing with Reconstructive Review.
\end{abstract}

\section{Background}

An eruption occurred during the second half of the 20th century that today has turned into an explosion of data and information. It's called the "internet." There it is, that oneword invention (sorry Al Gore, not yours) that pervades our lives to the point where it's hard to imagine life without it growing so fast that it's quickly becoming our main source of information and communication. This is true for all facets of our society, government, and industry, and medical publishing is certainly no exception.

Now that the world's data is literally at our fingertips it's more important than ever for authors to optimize digital content for relevant web searches. The concept of search optimization began in 1945 when Dr. Vannevar Bush wrote about creating a common archive for all the world's data. He published an article in The Atlantic proposing a "collection of data and observations, the extraction of parallel material from the existing record, and the final insertion of new material into the general body of the common record." [1] It wasn't until the 1990s (20 years, or so, after the dawn of the internet) that the idea spawned the development of the search engines that we know today. [2]

The number and nature of search engines on the internet is almost as overwhelming as the amount of information available. There are academic search engines like PubMed, Scopus, and Google Scholar as well as commercial ones like Google, Bing, and Yahoo. While differences exist between commercial, academic, and other types of search engines, they all do basically the same thing - using various "algorithms" to deliver the most relevant content to the top of the search results. Google by far is the biggest search engine with up to $77 \%$ of global searches. [3] It may not traditionally be used for academic research but it does return results from academic sites like PubMed and PubMed Central. So how does an author stand any chance of their work being found in this expanding sea of data?

\section{It Starts with the Keywords}

What are keywords and how many do I need? "Keywords are ideas and topics that define what your content is about. ...they are the words and phrases that searchers enter

Keywords: search engine optimization, medical publishing, keyword research

Educational Value \& Significance: JISRF Level B 
into search engines, also called 'search queries.' If you boil everything on your page - all the images, video, copy, etc. down to ... simple words and phrases, those are your primary keywords." [4] The tendency is to come up with too many keywords. Try to limit the number of words and phrases. While there is no perfect number, having dozens of them makes it impossible to effectively optimize one document.

Most online journals require authors to provide a list of keywords during the submission process. Many authors determine those keywords only after their article has been written - listing the most important keywords as an afterthought. There are specific tools online to help authors create a list of keywords based on what has been written. However, it would be better if authors spend a few minutes doing some simple keyword research before writing begins.

This research can turn up keywords (or terminologies) that have not been considered, even ones equally or more relevant to the subject matter. It may even reveal the misuse (or misspelling) of specific terms. In the March 2017 issue of Reconstructive Review Professor Panayot Tanchev of the Medical University of Sofia in Bulgaria commented on the correct use of terminology. "Medical terminology is an important tool for communication among medical practitioners, researchers, and scientists. The precise use of terms ensures a successful orientation in the field of medical practice contributing to the adequate treatment of patients." [5] While his comments were specifically about the use of "osteoarthritis" vs. "osteoarthrosis" the same precise use of terms is equally true for search optimization. If your article is targeting the wrong keywords, or even worse, misused or misspelled terms, it will be difficult for fellow researchers to find.

\section{Do Some Quick Research}

There are many ways to research keywords online and a great deal of time can be spent wandering down this rabbit hole. The easiest way to start is to search the internet as a researcher would looking for your work. Look at the results to make sure they are relevant to the subject of your article. If they are, then the words you used in the search will be important keywords. Keep an eye out for words or phrases that you haven't considered. Also be aware of the "predictions" that search engines provide as you are typing in your search (Figure 1). They provide alternative search words and phrases that are relevant to what is being searched and may need to be included in your own list of keywords.

Reconstructive Review joins most online medical journals in recommending that authors use Medical Subject Headings (MeSH) to find keywords. "MeSH is the Nation-

\section{Google Scholar}

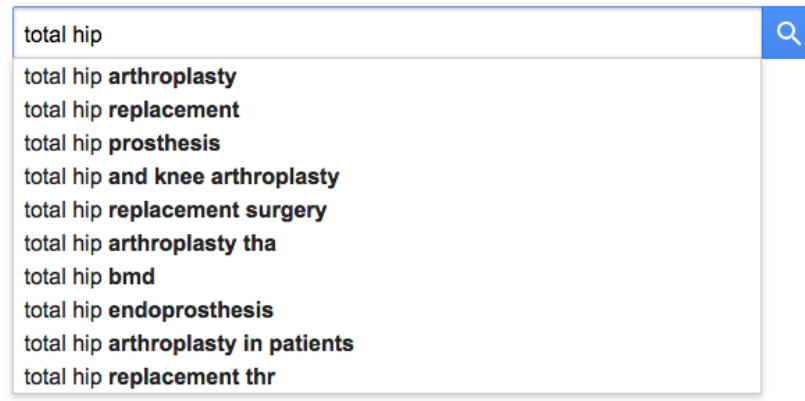

Figure 1. Screen capture of a Google Scholar search. Most search engines make predictions of what is being searched, providing alternative search words and phrases.

al Library of Medicine's controlled vocabulary thesaurus. It consists of sets of terms naming descriptors in a hierarchical structure that permits searching at various levels of specificity. MeSH descriptors are arranged in both an alphabetic and a hierarchical structure.” [] $]$ MeSH offers a couple of ways to find descriptors to use as keywords. MeSH on Demand is a tool that allows authors to input text from an abstract to automatically identify related MeSH terms. The MeSH browser is another tool that enables a direct search for related terms and descriptors using an existing list of keywords. For a complete description of the use of these tools visit the page titled "Suggestions for Finding Author Keywords using MeSH Tools" [7] on the National Library of Medicine's website.

\section{Make the Best Use of Keywords}

Once a list of keywords has been created put them in order of importance. Make sure to use the most important keyword, or words, at the beginning of the title and the abstract. Also be sure to use all of your keywords in the abstract because many online journals only display the title and abstract keeping the full text behind a login or a purchase point. While Reconstructive Review is open access and does not require a login or charge a fee to see the full text, the primary link to each article points to a summary page that contains the title, authors, abstract, keywords, list of references, and links to the full text in both PDF and HTML. So the first few keywords on the list should be used the most throughout the entire article and all keywords should be used in the title and abstract. Although it is important to use all your keywords throughout your article don't repeat them so much that it annoys your readers.

Finally, the importance of search optimization in medical publishing is only going to increase as the internet continues 
to grow - aggregating more and more of the world's data, increasing search competition and making it more difficult for published articles to be found. Temper your search optimization expectations with the following questions. Does your article add to the ongoing online conversation discussing the subject matter of your article? Is it unique? If so, make sure to highlight this in your list of keywords and in your writing. Articles with unique content should jump right to the top of search results. Whether or not your article faces stiff search competition don't forget to promote your work by linking to it from social media sites like Facebook, LinkedIn, ResearchGate, and Twitter, as well as any other personal or institutional websites. While these suggestions are relatively basic to the practice of search engine optimization for medical publishing they should not be overlooked if authors want any chance of their articles being discovered online.

\section{References:}

1. Zantal-Wiener, Amanda. "A Brief History of Search \& SEO.” HubSpot Blog, 27 Aug. 2017, 04:07:29, blog.hubspot.com/marketing/a-brief-history-of-search-seo.

2. Peter, Ian. "Ian Peter's History of the Internet." Www.nethistory.info, 2007, www. nethistory.info/History\%20of\%20the\%20Internet/index.html.

3. Allan, Robert. "Search Engine Statistics 2017." Smart Insights, 13 Apr. 2017, www.smartinsights.com/search-engine-marketing/search-engine-statistics/.

4. "What Are Keywords?” Moz, 4 Jan. 2018, moz.com/learn/seo/what-are-keywords.

5. Tanchev, Panayot. "Osteoarthritis or Osteoarthrosis: Commentary on Misuse of Terms." Reconstructive Review, Joint Implant Surgery \& Research Foundation, 31 Mar. 2017, http://dx.doi.org/10.15438/rr.7.1.178
6. "Medical Subject Headings (MESH $\left.{ }^{\circledR}\right)$ Fact Sheet.” U.S. National Library of Medicine, National Institutes of Health, 9 Nov. 2015, www.nlm.nih.gov/pubs/factsheets/mesh.html.

7. Suggestions for Finding Author Keywords Using MeSH Tools." U.S. National Library of Medicine, National Institutes of Health, 6 Jan. 2017, www.nlm.nih.gov/ mesh/authors.html.

\section{SUBMISSION HISTORY}

Submitted December 6, 2017

Reviewed December 7, 2017

Revised December 19, 2017

Accepted December 28, 2017

Published December 31, 2017

AUTHOR AFFILIATIONS

1 David Faroo

Joint Implant Surgery \& Research Foundation, Chagrin Falls, Ohio

(Direct inquires to David Faroo, dfaroo@jisrf.org)

AUTHOR DISCLOSURES

The authors declare there are no disclosures regarding the publication of this paper.

\section{COPYRIGHT \& OPEN ACCESS}

(C) 2017 Faroo. All rights reserved.

Authors retain copyright and grant the journal right of first publication with the work. Reconstructive Review is an open access publication and follows the Creative Commons Attribution-NonCommercial CC BY-NC. This license allows anyone to download works, build upon the material, open 6 access and share them with others for non-commercial purposes as

long as they credit the senior author, Reconstructive Review, and the Joint Implant Surgery \& Research Foundation (JISRF). An example credit would be: "Courtesy of (senior author's name), Reconstructive Review, JISRF, Chagrin Falls, Ohio".

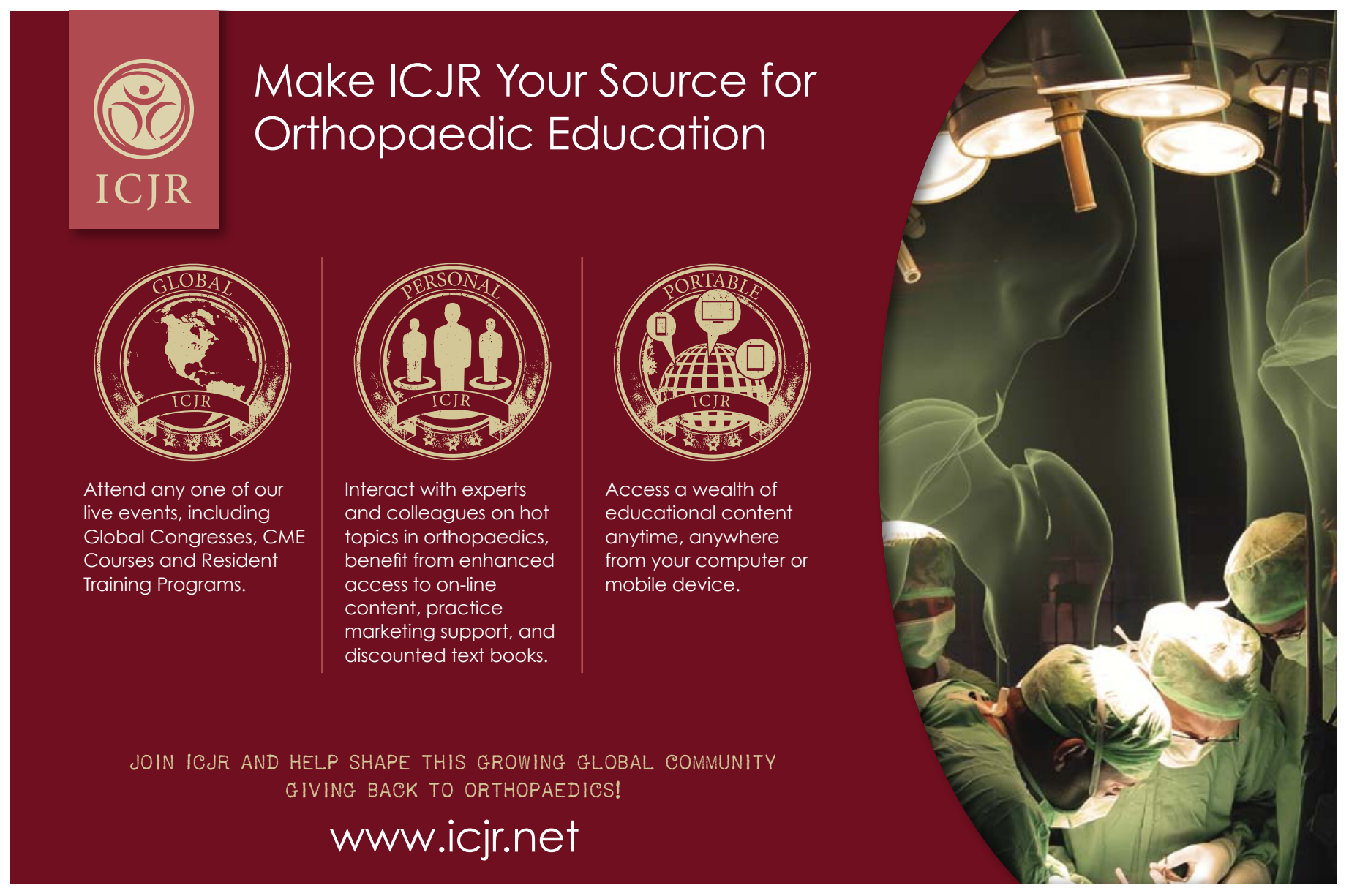

